\title{
Optical properties of ion implanted thin Ni films on lithium niobate
}

\author{
V.O. Lysiuk ${ }^{1,2}$, V.S. Staschuk ${ }^{2}$, I.G. Androsyuk ${ }^{1}$, N.L. Moskalenko ${ }^{1}$ \\ ${ }^{1} V$. Lashkariov Institute of Semiconductor Physics, NAS of Ukraine, \\ 41, prospect Nauky, 03022 Kyiv, Ukraine \\ ${ }^{2}$ Taras Shevchenko Kyiv National University, Department of Physics, \\ 2, prospect Glushkova, 03022 Kyiv, Ukraine \\ E-mail:lysiuk@univ.kiev.ua
}

\begin{abstract}
Ion implantation by $\mathrm{keV} \mathrm{Ar}^{+}$ions creates blisters on the surface of thin $\mathrm{Ni}$ films deposited on lithium niobate and causes changes in optical properties and structure of Ni film and lithium niobate substrate. Processes of ion implantation and effects of increasing absorption, adhesion, damage threshold are described and explained in the paper. Development of pyroelectric photodetector "thin Ni film - lithium niobate" is proposed.
\end{abstract}

Keywords: ion implantation, thin Ni films, lithium niobate, optical properties.

Manuscript received 02.09.10; accepted for publication 02.12.10; published online 28.02.11.

\section{Introduction}

Thin metal films on lithium niobate are widely used in infrared optoelectronics and known as high-sensitive systems of pyroelectric detectors, modulators, and power meters [1]. More sensitive triglycine sulfate and its isomorphic compounds have lower degradation stability what is unacceptable in a number of applications [2]. Weak adhesion of absorbing films to lithium niobate causes limitation of system application with power lasers. Usually, intensities over $2 \mathrm{~W} / \mathrm{cm}^{2}$ destroy absorbing coatings on the pyroelectric substrate [3]. Increasing adhesion of a metal film to lithium niobate by adding some transition layer is not permitted because of disfiguration of optical properties of the sample by $3 \mathrm{rd}$ compound. That is why, the method of ion implantation by ions of inert gas was selected for improvement mechanical and optical properties of the samples. Ion implantation stimulates defects generation, radiation-accelerated diffusion and other related effects by changing the surface structure of absorbing films and sub-surface layer of pyroelectric crystal. For this purpose, it was necessary to: 1) calculate energy and dose of selected ions for their maximal distribution at the interface film-substrate after implantation; 2) develop technology for sample preparation and processing; 3) investigate optical properties of ion implanted thin metal films on lithium niobate, compare with non-implanted and provide appropriate interpretation.

\section{Experimental}

$\mathrm{Ar}^{+}$ions were selected for ion implantation as the easiest and cheapest to obtain for environment. To determine the distribution function for $\mathrm{Ar}^{+}$ions and recoil atoms as a dependence on the ion energy, calculation of ion stopping ranges was made using the Monte-Carlo method [4] for Ni films on lithium niobate substrate. As shown in Fig. 1, the maximum number of ions accelerated to $50 \mathrm{keV}$ stops at the depth of $20 \mathrm{~nm}$ from the sample surface, what corresponds to the interface film-substrate, if the film thickness is $20 \mathrm{~nm}$. And for ion energies of 100 and $150 \mathrm{keV}$, the stopped ion distribution peak will be at 40 and $60 \mathrm{~nm}$ from the sample surface, accordingly. The optimal ion dose should be within $10^{15}$ to $10^{16} \mathrm{~cm}^{-2}$. Obtained results were used for production of and processing the samples.

Slices of lithium niobate single crystal with the thickness of $100 \mu \mathrm{m}$ were coated by $\mathrm{Ni}$ films with thicknesses $15,20,30$, and $40 \mathrm{~nm}$ by using the ion plasma method [5]. Every second sample was implanted by $\mathrm{Ar}^{+}$ ions with energies from 50 to $100 \mathrm{keV}$ in dependence on its thickness according to Monte-Carlo calculations.

Spectral investigations (transmission and reflectance) were made using UR-20 spectrophotometer in the wide wavelength range from 0.2 to $15 \mu \mathrm{m}$ varying source of light from quartz lamp to globar as well as prism of monochromator. Surface structure of the samples was investigated using DGSM-35 and Zeiss Ultra Scanning Electron Microscopies. 


\section{Results and discussion}

Spectral investigations have shown that two absorption bands are observed for thin $\mathrm{Ni}$ films on lithium niobate substrate near $\lambda=5.5 \mu \mathrm{m}$ and $6.2 \mu \mathrm{m}$ (Fig. $2 \mathrm{a}$ ), which can be related with presence of $\mathrm{H}-\mathrm{O}-\mathrm{H}$ groups in $\mathrm{LiNbO}_{3}$ and by oscillation of $\mathrm{H}_{2} \mathrm{O}$ molecular complexes and other inclusions. In the wavelength range near $\lambda=10.5 \mu \mathrm{m}$, an intense absorption band causes decrease in transmission. This band is related with valence bridge oscillations of oxygen in the octahedron $\mathrm{NbO}_{6}$. These oscillations are fundamental phonons of lithium niobate single crystal [6].

The observed shift of the main absorption band from 11 to $10 \mu \mathrm{m}$ in implanted $\mathrm{Ni}$ films on lithium niobate, as compared with non-implanted ones, is related with damaging the oxygen octahedron $\mathrm{NbO}_{6}$ in the subsurface layer of lithium niobate single crystal during ion implantation. Bridges $\mathrm{Nb}-\mathrm{O}-\mathrm{Nb}$ are destructed. And valence bridge-like oscillation $\mathrm{Nb}-\mathrm{O}-\mathrm{Nb}$ transforms to regular valence oscillation $\mathrm{Nb}-\mathrm{O}-\mathrm{Nb}$, the frequency of which is increased, and the peak wavelength shifts to $10.2 \mu \mathrm{m}$.

As shown in Fig. 2a, ion implantation causes rise of transmission of $\mathrm{Ni}-\mathrm{LiNbO}_{3}$ in visible and near infrared ranges $(0.4-6.0 \mu \mathrm{m})$, what is the result of widening the transitional layer film-substrate owing to intensive ion intermixing at this interface as well as disordering and amorphization of $\mathrm{Ni}$ film and subsurface layers of lithium niobate substrate.

Results of spectral investigations of reflectance for $\mathrm{Ni}-\mathrm{LiNbO}_{3}$ have shown that the reflection coefficients decrease within the whole spectral range after ion implantation [7]. The maximal difference between nonimplanted and implanted samples is $40 \%$ for the Ni film with the thickness of $15 \mathrm{~nm}$. Comparing the optical properties with surface structure of the implanted and non-implanted samples, it is visible that decrease of reflectance spectra may be related with creation of a rough surface as a result of blister formation and decrease of heterogeneity of the interface film-substrate.

$\mathrm{N}$, rel. un.

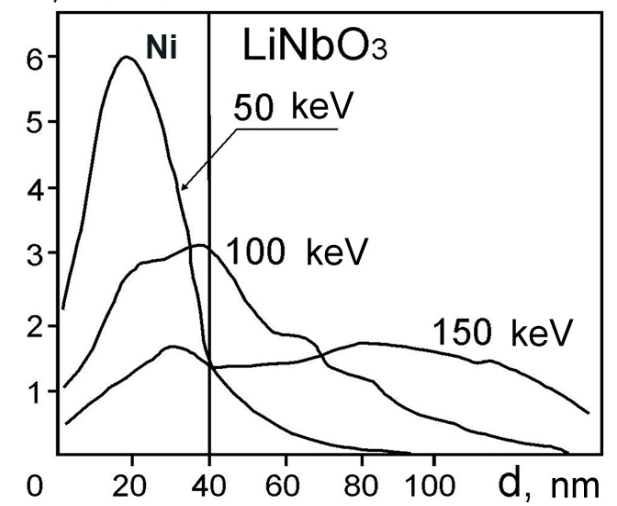

Fig. 1. Distribution of implanted $\mathrm{Ar}^{+}$ions along the depth (energy 50,100, and $150 \mathrm{keV}$ ) in the system thin Ni film lithium niobate substrate.
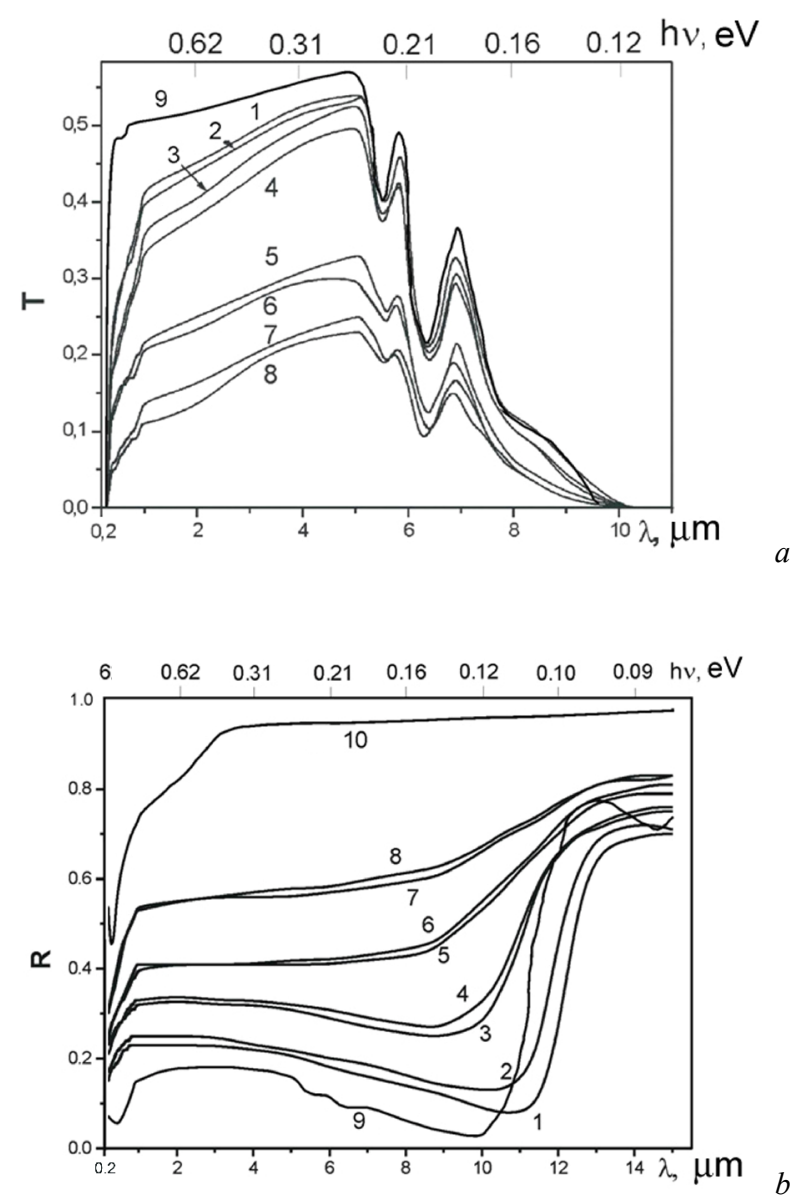

Fig. 2. Transmission $(a)$ and reflectance $(b)$ spectra of a thin $\mathrm{Ni}$ film with thicknesses of $15(1,2), 20(3,4), 30(5,6)$, and $40 \mathrm{~nm}(7,8)$ before $(1,3,5,7)$ and after ion implantation $(2,4$, $6,8)$ in comparison with lithium niobate single crystal $(9)$ and bulk Ni (10).

As shown by SEM investigations (Fig. 3), smooth thin $40-\mathrm{nm} \mathrm{Ni}$ film on lithium niobate before ion implantation (a) totally differs from the same sample after $100 \mathrm{keV} \mathrm{Ar}^{+}$ion (b), where blisters with the average dimension of $1 \mu \mathrm{m}$ in diameter are observed, and amorphization of Ni film and subsurface layer of lithium niobate was observed using X-ray analysis.

Blisters appear as a result of argon exit from the film depth during thermal annealing after ion implantation [8]. Their formation makes surface rough and increases absorption of the surface coating. High coefficient of surface tension damage threshold doesn't allow blisters to prevent argon exit. Additionally, investigations have shown that adhesion between $\mathrm{Ni}$ film and $\mathrm{LiNbO}_{3}$ substrate becomes at least two orders higher after ion implantation. This makes damage threshold of the samples over $50 \mathrm{~W} / \mathrm{cm}^{2}$. These advantages can be used for development of sensing system with enhanced radiation stability and sensitivity on the base of proposed implanted thin Ni films on lithium niobate [9]. 

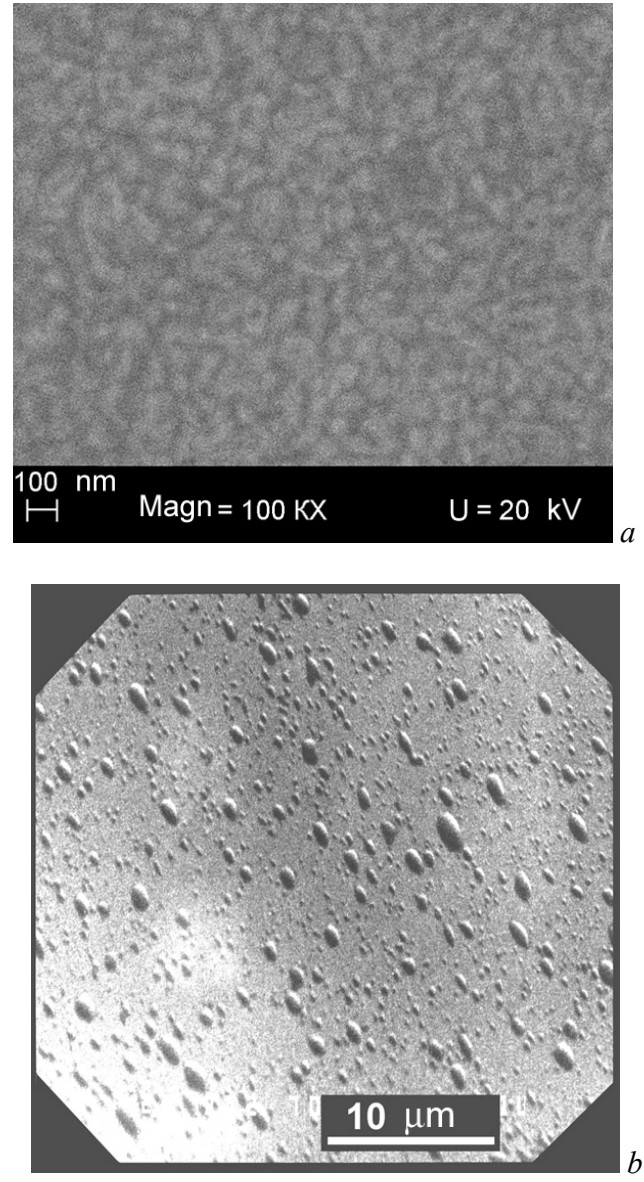

Fig. 3. SEM image of thin Ni film $(40 \mathrm{~nm})$ on lithium niobate before ion implantation by $\mathrm{Ar}^{+}$ions (a) and after it (b).

\section{Conclusion}

It is found that ion implantation of thin $\mathrm{Ni}$ films on lithium niobate decreases reflectance and increases absorption in the wide wavelength range $(\lambda=0.2$ $15 \mu \mathrm{m})$ as a result of: 1) blisters formation on the samples surface, increase of diffuse scattering and absorption of the sample; 2) decrease of heterogeneity on the interface film-substrate by ion intermixing; 3) amorphization of subsurface layer of film and substrate.

Ion implantation destroys valence bridge bonds $\mathrm{Nb}-\mathrm{O}-\mathrm{Nb}$ and transforms corresponding oscillations to regular valence oscillations $\mathrm{Nb}-\mathrm{O}$, increasing frequency. Ion implantation led to bubble-like blisters formation with the average diameter of about $1 \mu \mathrm{m}$.
A sensing system based on the structure thin $\mathrm{Ni}$ film - lithium niobate implanted by $\mathrm{Ar}^{+}$ions has been developed for application in pyroelectric photodetectors. Their characteristics such as sensitivity, detectivity, radiation stability, time constant, durability do not yield a point to the corresponding characteristics of the best analogues.

The work is a part of scientific research on topic "Optical and magneto-optical properties of surface layers and films with different type of conductivity", registration number 06 БФ 051-10, 2006-2010.

\section{References}

1. H. Chaib, T. Otto, and L.M. Eng, Electrical and optical properties of $\mathrm{LiNbO}_{3}$ single crystals at room temperature // Phys. Rev. B, 67, 174109 (2003).

2. J. Novotny, B. Brezina, and J. Zelinka, Growth and characterization of TGS and DTGS single crystals doped with $\mathrm{Pt}(\mathrm{II}), \mathrm{Pt}(\mathrm{IV})$ and L-alanine // Cryst. Res. Technol. 39, No.12, p. 1089-1098 (2004).

3. R. Watton, Ferroelectric materials and devices in infrared detection and imaging // Ferroelectrics, 91, No.1-4, p. 87-108 (1988).

4. G. Hobler, S. Selberherr, Monte Carlo simulation of ion implantation into two- and three-dimensional structures // IEEE Trans. Computer-Aided Design of Integrated Circuits and Systems, 8, No.5, p. 450459 (1989).

5. L.M.P. Pinheiro et al., Structure, morphology and composition of thin $\mathrm{Pd}$ and $\mathrm{Ni}$ films deposited by dc magnetron sputtering on polycrystalline $\mathrm{Ni}$ and Pd foils // J. Phys. D: Appl. Phys. 38, p. 4241-4244 (2005).

6. V. Caciuk, $\mathrm{Ab}$ initio zone-center phonons in $\mathrm{LiTaO}_{3}$ : Comparison to $\mathrm{LiNbO}_{3} / /$ Phys. Rev. B, 64, 224303 (2001).

7. V.O. Lysiuk, N.L. Moskalenko, V.S. Staschuk et al., Formation of blisters in thin metal films on lithium niobate implanted by $\mathrm{keV} \mathrm{Ar}^{+}$ions // Semiconductor Physics, Quantum Electronics \& Optoelectronics, 13(1), p. 103-109 (2010).

8. S.G. Mayr and R.S. Averback, Effect of ion bombardment on stress in thin metal films // Phys. Rev. B, 68, 214105 (2003).

9. J. Lehman, E. Theocharous, G. Eppeldauer, and C. Pannell, Gold-black coatings for freestanding pyroelectric detectors // Meas. Sci. Technol. 14, p. $916-922$ (2003). 